\title{
Cellebrating DNA Double Helix-the Last 60 Years of Molecular Biology
}

\section{Miguel Angel Medina*}

Department of Molecular and Biochemistry, University of Malaga, Malaga, Spain and CIBER de Enfermedades Raras (CIBERER), Malaga, Spain

The term Molecular Biology was coined by the mathematician Warren Weaver while being the director of the Division of Natural Sciences at the Rockefeller Foundation in 1938 to mention, more than a coherent new scientific discipline, the concept of understanding the life from the laws of physics and chemistry. However, very soon the convergence of biochemistry and genetics decisively contributed to the emergence of molecular biology as a new discipline throughout the forties. April $25^{\text {th }}, 1953$ was a key date for the early history of molecular biology with the simultaneous publication in Nature of three milestone articles elucidating the molecular structure of nucleic acid [1-3]. The simple and schematic cartoon of the DNA double helix structure contained in the contribution by Watson and Crick [1] and the X-ray difractogram obtained by Rosalind Franklin [3] upon which that cartoon was based have become icons of the modern scientific culture. Since that date, a prolonged golden age of molecular biology has extended up to date. The genetic code was quickly uncovered. Protein structures have been solved and their relationships with their functions have been investigated in great detail. From the middle of the seventies, the scientific-technological revolution of recombinant DNA has changed biology and has contributed to push it to its current exceptional forefront position, ahead of all the scientific disciplines. The launching of the genome projects, the emergence of bioinformatics, the new "omics" in the post-genomic era have contributed to the deep changes that have transformed biology in the most expanding scientific discipline at the beginning of the XXI Century. In the last few years, the new interdisciplinary areas of synthetic and systems biology have emerged and grown very fast, opening new scenarios for the development of molecular biology. All this began 60 years ago with the aforementioned three articles in Nature. There are good reasons to celebrate in 2013 their publication 60 years ago. During this year, this old wise man called Sydney Brenner (one of the pioneers and "fathers" of modern molecular biology) has offered in several locations throughout the world a lecture entitle Molecular Biology- Its Last 60 Years. The past September $6^{\text {th }}$, attendees to the XXVI Congress of the Spanish Society of Biochemistry and Molecular Biology had the opportunity to be delighted with such a lecture, given as the closing plenary lecture of the Congress. Dr. Brenner claimed to look into the past to through light to the future possible developments of molecular biology, let's say for its next 60 years.

We do not need a magic crystal ball to foresee that the immediate next big challenge of molecular biology will be that of big data. The huge amount of data that current biology is able to produce is making continuously growing the gap between the amount of available scientific data and the actual new knowledge generated from these data [4]. In fact, big data is already a problem, a challenge, a reality and an opportunity for further development of molecular biology. An expanded long-lived golden age of molecular biology is just coming.

\section{Acknowledgement}

The experimental work in my research group is not supported currently by any active grant, but limited funds from group BIO-267 (Andalusian Government and FEDER). The "CIBER de Enfermedades Raras" is an initiative from the ISCIII (Spain).

\section{References}

1. Watson JD, Crick FHC (1953) A structure for deoxyribose nucleic acid. Nature 171: 737-738.

2. Wilkins MHF, Stokes AR, Wilson HR (1953) Molecular structure of deoxypentose nucleic acids. Nature 171: 738-740.

3. Franklin RF, Gosling RG (1953) Molecular configuration in sodium thymonucleate. Nature 171: 740-741.

4. Medina MA (2013) Systems biology for molecular life sciences and its impact in biomedicine. Cell Mol Life Scie 70: 1035-1053. *Corresponding author: Miguel Ángel Medina, Department of Molecular and
Biochemistry, University of Málaga, Málaga, Spain and CIBER de Enfermedades
Raras (CIBERER), Málaga, Spain, Tel: +34-952137132; Fax: +34-952132000;
E-mail: medina@uma.es

Received October 23, 2013; Accepted October 26, 2013; Published October 30 2013

Citation: Medina MA (2013) Cellebrating DNA Double Helix-the Last 60 Years of Molecular Biology. Mol Biol 2: e111. doi:10.4172/2168-9547.1000e111

Copyright: (c) 2013 Medina MA. This is an open-access article distributed under the terms of the Creative Commons Attribution License, which permits unrestricted use, distribution, and reproduction in any medium, provided the original author and source are credited. 